\title{
Empiric Study on Reverse Logistic Strategies in the Manufacturing Sector in the Central Area of Cuba
}

\author{
Michael Feitó Cespón \\ Faculty of Industrial Engineering \\ Central University of Las Villas, Cuba \\ michaelfc@uclv.edu.cu \\ Roberto Cespón Castro \\ Faculty of Industrial Engineering \\ Central University of Las Villas, Cuba \\ rcespon@uclv.edu.cu \\ Janerik Lundquist \\ Department of Production Economics Linköping University, Sweden \\ janerik.lundquist@liu.se
}

\begin{abstract}
The growing need of correct implementation of reverse logistic strategies in the modern company, along with the ignorance of their tendency and behavior in the manufacturing sector in the central area of Cuba, make possible the develop of this study. The main objective is to identify a generic configuration on reverse logistic strategies in manufacturing companies from the Cuban central area. As a result, this research detects the existence of three generic reverse logistic strategies which are: recapturing value, environmental and commercial strategies.
\end{abstract}

Keywords: Logistics, Reverse logistics, environmental care.

\section{INTRODUCTION}

Human kind in its way through history has underestimated the action against nature, assuming the environment as infinite and inextinguishable. The technological and industrial advances in most cases do not respect the necessary harmony between men and nature causing an ecological crisis. It is needed a sustainable and environmentally responsible manufacturing that integrates the profit and efficiency orientation with broader considerations of the company's internal and external stakeholders and its environmental impact. The evolution towards sustainable Operation Management $(\mathrm{OM})$ is clear in three areas: Green product and process development; Lean and green OM; Remanufacturing and closedloop supply chains (Kleindorfer et all, 2005).

Residual and product returns management has become a great challenge for economists and engineers in business world. It is a necessity its recovery as original row material substitute due to the conse- quences that these residuals might have in environment deterioration. The reverse logistic appears as a good strategic tool for that purpose (Alshamrani et all, 2008). In literature there are several concepts about reverse logistics which have some differences among them. To the Reverse Logistics Executive Council, reverse logistics is the process of planning, implementing, and controlling the efficient, cost effective flow of raw materials, in-process inventory, finished goods and related information from the point of consumption to the point of origin for the purpose of recapturing value or proper disposal (Rogers and Tibben-Lembke, 1998). It is noticeable the emphasis in the direction of the material flow from typical destination to the origin and the purpose of take economic advantage of reverse logistic. For the Revlog group in Europe, Reverse Logistics refers to all logistic activities to collect, to disassemble and process used products, product parts, and/ or materials in order to ensure a sustainable (environmentally friendly) recovery (REVLOG, 2007). 
This group gives more importance to the environmental purpose and distinguishes reverse logistic as a strategic tool for sustainability.

The manufacturing sector is an important residual generator with around the 30 percent of solid waste in the central area in Cuba. This sector is compound by more than 300 companies, where are remarkable the Chemical Industry, the Metallurgic Industry and the Sugar Industry among others. The lack of knowledge about behavior of residual and returns management in manufacturing companies of central area, in Cuba, is the problem that this research deals with. So the authors will prove the hypothesis that the industrial sector has reverse logistic strategies to manage returns and residuals based on different criteria which allow the formation of differenced generic strategies company groups. That's why the main objective of this research is to carry out an empirical study about reverse logistic strategies, based on collected data of manufacturing companies in the center of Cuba, to achieve a generic classification of these strategies, and also to describe the formulation and formalization characteristics of the reverse logistic strategies present in the studied sector.

\section{CHARACTERISTICS OF REVERSE LOGISTIC STRATEGIES}

The reverse logistic strategies can be conditioned by some factor that may stimulate them or not (TibbenLembke, 2002) such as the dimension of the companies, the kind of product and clients, the strategies of manufacturing followed by the company, the position of the company in the market, the behavior of the substitute markets for those products that are repaired or restored, the different stages of the products cycle of life and so forth.

The reverse logistic strategies are mostly characterized by the needs which are satisfied with the strategy. These needs may determine notable differences most of all in the strategy cost-benefit estimation, the kind of products or materials that are collected and the activities that would be made with those products once they are back in the company (Sinnecker, 2007). Every time a reverse logistic strategy is developed, is quite important to define clearly the reasons why this strategy is necessary. Some possible reasons why the enterprises in the world make reverse logistic strategies are explained in the literature (Rogers and Tibben-Lembke, 1998; Lau et al, 2004; GonzálezTorre, AdensoDíaz and Artiba, 2004). These reasons can be grouped in three main reasons: environmental, marketing and economic reasons.

According to the design of the reverse logistic strategy in any manufacturing company, many different objectives can be stated. Those objectives can be present indistinctively in one or another strategy; this is the reason why the correspondence objectivestrategy depends completely on the importance level that can be granted to those objectives in the company. According to the author's opinion, some of the objectives which might be present in reverse logistic strategies are listed below:

- To maximize the value-added to products and materials returned to the company.

- To minimize the return cost of the products or materials, this means the optimum efficiency of the reverse logistic network.

- To minimize the environmental impact of those products and materials.

- To increase the service to the client.

- To reduce the cost of production.

Related to the objectives there is another important strategic aspect which is the elaborated polices that help to fulfill the objectives in more efficient way. The consulted literature covers some manufacturing polices that have been applied by several companies all over the world (Rogers and Tibben-Lembke, 1998, Lau et al, 2004). Those policies are related below:

- Simplification and standardization of materials

- Identification of the materials

- Design products for easy disassembling

- Design for the reutilization

\section{CLASSIFICATION OF GENERIC REVERSE LOGISTIC STRATEGIES IN MANUFACTURING COMPANIES OF THE CUBAN CENTRAL AREA}

Since the main objective of this research is to carry out a reverse logistic strategies classification in the manufacturing sector in the Cuban central area, it is necessary to develop a procedure that guides this research methodologically. The methodology followed in the empirical studies on manufacture strategies in Spanish companies (Diaz et al, 2004) were the bases to design the procedure to follow in this research. 
The procedure steps are listed below.

1. Selection of population and sample size for the study

2. Design of questionnaire for data collection

3. Validation of collected data

4. Cluster analysis

5. Validation of the formed groups

6. Description of the group profiles

\section{Definition of the population and the sample size}

The information obtained in this study comes specifically from primary sources used only for this research. Since the main objective is the analysis of the reverse logistic strategies of the manufacturing companies located in the Cuban central area, the population studied is integrated by the manufacturing companies (323 companies) that exert their productive activity in all the territory according to the Cuban Statistics Center. The questionnaire was delivered to the administrative personnel who are involved in the reverse logistic planning in each company for the entire studied population, being 192 the number of companies that answer the survey correctly for the $59 \%$ of the studied population. It was a self-selected (non-probabilistic) sampling, and the sample size was not defined by the researcher but was defined by the correct filled formularies. For similar survey studies made on manufacturing strategies, a sample of $20 \%$ and even the $15 \%$ of the studied population are used to complete the research (Grande \& Abascal, 1999).

\section{Design of the questionnaire for data collection}

One of the basic ways to obtain information is formulating questions to those people who can offer it; this method of data collection is called 'Survey'. A structured questionnaire is designed for this study, in which some aspects of the formulation as well as the content of the reverse logistic strategy are included. This questionnaire contains the investigation variables to collect the information from the questioned personnel; it has been designed in order to get the information fully structured, with high formalization and standardization degree in questions and possible answers.

The main structure of the formulary is divided into four parts. The first part consists of a question battery related to the general information of the company. These questions give a general characterization of the company. Table 1 shows the variables related with this set of questions and the criteria for homogenize them into the same scale. To complete this step a scale of three levels is designed, that evaluates the variables from 1 to 3 , where 3 represents more importance or complexity than 1 . The criteria to rescale the variables were defined by the authors (Feitó, 2007) and validated by an expert group of professors of the Central University of Las Villas. These criteria may be applied in studies of manufacturing companies of Cuba. For studies in other countries might be needed to redefine them.

Table 1- Homogenization of variables used in the study related in the first part of the formulary.

\begin{tabular}{|c|c|c|c|c|}
\hline \multirow{2}{*}{ Variables } & \multirow{2}{*}{ Variable Attributes } & \multicolumn{3}{|l|}{ Scale / Criteria } \\
\hline & & 1 & 2 & 3 \\
\hline \multirow{2}{*}{ Company Size } & Workers quantity & $<50$ small & 50-250 medium & $>250$ large \\
\hline & Annual sales (Million USD) & $<1$ small & 1-10 medium & > 10 large \\
\hline \multirow{3}{*}{$\begin{array}{l}\text { Company competitive } \\
\text { status }\end{array}$} & Norm Certifications & None & - & At least one \\
\hline & $\begin{array}{l}\text { Qualification of Human } \\
\text { Resources }\end{array}$ & Not qualified & Qualified & $\begin{array}{l}\text { Highly } \\
\text { qualified }\end{array}$ \\
\hline & Technology Updating & Outdated & $\begin{array}{l}\text { Mix of } \\
\text { technologies }\end{array}$ & Updated \\
\hline
\end{tabular}

In the second part, the questions are focused on the supply chain complexity degree, obtaining a holistic vision about the supply chain (Carter and Ellram, 1998). Table 2 shows the set of variables used to describe the complexity degree of the supply chain in which the company is involved. 
Table 2- Homogenization of variables used in the study related in the second part of the formulary.

\begin{tabular}{|l|l|l|l|l|}
\hline \multirow{4}{*}{ Variables } & Variable Attributes & Scale / Criteria & $\mathbf{2}$ & $\mathbf{3}$ \\
\cline { 2 - 5 } & Suppliers quantity & $\mathbf{1}$ & $10-20$ & $>20$ \\
\hline \multirow{4}{*}{$\begin{array}{l}\text { Supply chain } \\
\text { complexity }\end{array}$} & Customers quantity & $<10$ & $10-20$ & $>20$ \\
\cline { 2 - 5 } & Shipment distances & $\begin{array}{l}\text { Inside of the } \\
\text { Province }\end{array}$ & $\begin{array}{l}\text { Inside of Cuban } \\
\text { Territory }\end{array}$ & $\begin{array}{l}\text { Outside Cuban } \\
\text { Territory }\end{array}$ \\
\cline { 2 - 5 } & $\begin{array}{l}\text { Information } \\
\text { Requirements }\end{array}$ & $\begin{array}{l}\text { Simple or not } \\
\text { defined }\end{array}$ & Complex & Very Complex \\
\cline { 2 - 5 } & Product variety & $<5$ & $5-10$ & $>10$ \\
\cline { 2 - 5 } & Seasonal demand & None & In some products & In all products \\
\hline
\end{tabular}

The third part of the formulary characterizes the formulation process of the reverse logistic strategy and its performance within the competitive framework of the company. It also offers a vision of the complexity of the reverse supply chain (Chaves and Martins, 2005). The variables related to the reverse supply chain complexity are shown in Table 3.

Table 3- Homogenization of variables used in the study related in the third part of the formulary.

\begin{tabular}{|c|c|c|c|c|}
\hline \multirow{2}{*}{ Variables } & \multirow{2}{*}{ Variable Attributes } & \multicolumn{3}{|l|}{ Scale / Criteria } \\
\hline & & 1 & 2 & 3 \\
\hline \multirow{6}{*}{$\begin{array}{l}\text { Reverse supply } \\
\text { chain complexity }\end{array}$} & Variety of residuals & $<1$ & 1- 5 & $>5$ \\
\hline & Residuals quantity & $\begin{array}{l}<2 \% \text { of production } \\
\text { volume }\end{array}$ & $2-5 \%$ & $>5 \%$ \\
\hline & $\begin{array}{l}\text { Information } \\
\text { requirements }\end{array}$ & $\begin{array}{l}\text { Simple or not } \\
\text { defined }\end{array}$ & Complex & Very Complex \\
\hline & $\begin{array}{l}\text { Devolution Shipment } \\
\text { distances }\end{array}$ & $\begin{array}{l}\text { Inside of the } \\
\text { Province }\end{array}$ & $\begin{array}{l}\text { Inside of Cuban } \\
\text { Territory }\end{array}$ & $\begin{array}{l}\text { Outside Cuban } \\
\text { Territory }\end{array}$ \\
\hline & $\begin{array}{l}\text { Dangerous } \\
\text { environmental } \\
\text { residuals }\end{array}$ & No & - & Yes \\
\hline & $\begin{array}{l}\text { Presence of } \\
\text { Classification Centers }\end{array}$ & No & - & Yes \\
\hline
\end{tabular}

Finally, information about the reasons for the formulation of reverse logistic strategies, the objectives derived from the strategy and the manufacturing policies associated with the reverse logistic strategy is requested, the variables related with this questions are shown in Table 4. 
Table 4- Homogenization of variables used in study related in the fourth part of the formulary.

\begin{tabular}{|c|c|c|c|c|}
\hline \multirow{2}{*}{ Variables } & \multirow{2}{*}{ Variable Attributes } & \multicolumn{3}{|c|}{ Scale / Criteria } \\
\hline & & 1 & 2 & 3 \\
\hline \multirow{10}{*}{$\begin{array}{l}\text { Strategic status } \\
\text { of reverse } \\
\text { logistics }\end{array}$} & $\begin{array}{l}\text { Importance granted to: the } \\
\text { competitive reason }\end{array}$ & None & Medium & High \\
\hline & The environmental reason & None & Medium & High \\
\hline & Recapturing value reason & None & Medium & High \\
\hline & $\begin{array}{l}\text { Objective to maximize value added } \\
\text { of residuals. }\end{array}$ & None & Medium & High \\
\hline & $\begin{array}{l}\text { Objective to decrease the cost of } \\
\text { residuals returns. }\end{array}$ & None & Medium & High \\
\hline & $\begin{array}{l}\text { Objective to decrease the } \\
\text { production costs. }\end{array}$ & None & Medium & High \\
\hline & $\begin{array}{l}\text { Objective to improve the client } \\
\text { service rate. }\end{array}$ & None & Medium & High \\
\hline & $\begin{array}{l}\text { Objective to maximize the value } \\
\text { added to returns. }\end{array}$ & None & Medium & High \\
\hline & $\begin{array}{l}\text { Objective to minimize the } \\
\text { environmental impact of residuals }\end{array}$ & None & Medium & High \\
\hline & $\begin{array}{l}\text { Objective to decrease the cost of } \\
\text { devolution returns. }\end{array}$ & None & Medium & High \\
\hline
\end{tabular}

Validation of the data collected

The alpha (Cronbach) is a reliability analysis used for the validation of the surveys answered. This statistic expresses the correlation between variable sets that's why it is necessary to define groups of questions related among them. The value of the coefficient alpha should be greater than 0.7 to be able to use the data collected. This test is applied to each group of questions. The correlation coefficients are greater than 0.70 for every case as it is shown in Table 5, which indicates that the data collected in the survey are statically reliable and can be used in further analysis and it is possible to go forward with the empiric study.

Table5 - Results of reliability analysis

\begin{tabular}{|l|c|c|}
\hline \multicolumn{1}{|c|}{ Variables } & Variable attributes & Cronbach Alpha \\
\hline Company Size & 2 & 0.9444 \\
\hline Company competitive status & 3 & 0.7066 \\
\hline Supply chain complexity & 6 & 0.7565 \\
\hline Reverse supply chain complexity & 6 & 0.7599 \\
\hline Strategic status of reverse logistics & 10 & 0.8340 \\
\hline
\end{tabular}

Formation of company clusters using hierarchical cluster analysis

The main objective of this research is the classification of the companies in the Cuban central area according to the type of reverse logistic strategy for the management of their returns and residuals. The creation of homogeneous clusters and the description of each group profile complete this objective. Some decisions have to be made to form groups using the multivariable hierarchical cluster analysis, these are: Selecting the variables that will be used in the cluster 
analysis; defining the criterion to measure the distances between the variables; choosing the grouping method and defining the quantity of homogeneous groups formed by the cluster analysis.

The first step is to choose the variables that will be the comparative elements that serve to define the groups. Fourteen variables are taken into account: Company size, Competitiveness, Complexity of the forward and Complexity of the reverse supply chains, three main reasons for developing reverse logistic strategies and seven objectives that can be present in the reverse logistic strategies. The variables: Company size, Competitiveness, Supply chain complexity and Reverse supply chain complexity are formed through the analysis of their attributes and they are used in the cluster formation in this way, contrary in the case of the variable: Strategic status of reverse logistic, all their attributes are used as variables in the cluster analysis, giving relevant information to describe each group profile.

Next, the measure criterion to estimate the distance between the variables used in the cluster analysis is defined. Several methods can be used to measure this distance that can differ according to the type of variables (ordinal, binary or continuous). In this research the criterion used is the Square Euclidian distance (Cespón and Ibarra, 2003). This method computes the quadratic range between pairs of objects (companies in this case).

The other parameter needed for the cluster analysis is the aggregation algorithm. In the software there appear several of algorithms such as: nearest neighbor, media clustering, between group's relationship and centroid clustering. In this research, an agglomerative hierarchic method called "Centroid clustering" is selected. This method computes the gravity center of each cluster and later it starts to include the cases, step by step, until all of them are grouped in a big cluster.

Several solutions can result from the cluster analysis, so several decisions can be made:

1. To treat each case separately.

2. To combine them all together.

3. Some intermediate variants. The most usual one is to establish an intermediate variant between 2 and 5 groups

The cluster analysis make possible the classification of the companies studied into three groups, each one represents an alternative of reverse logistic strategy. A visual inspection of the dendrogram graph evidences the formation of three groups. These groups that have been obtained are made up of 102, 48 and 42 companies respectively. So it has been possible to identify three types of strategies: Recapturing value, Environmental and Commercial strategies as it is shown in Figure 1. The existence of a remarkable difference between the amount of companies that make up the first group and the rest ones indicates that inside the three different types of reverse logistic strategies, the companies studied have a noticeable tendency to develop specifically the Recapturing value strategy.

\section{Figure 1- Reverse logistic strategic behavior in the industry in studied area in Cuba}

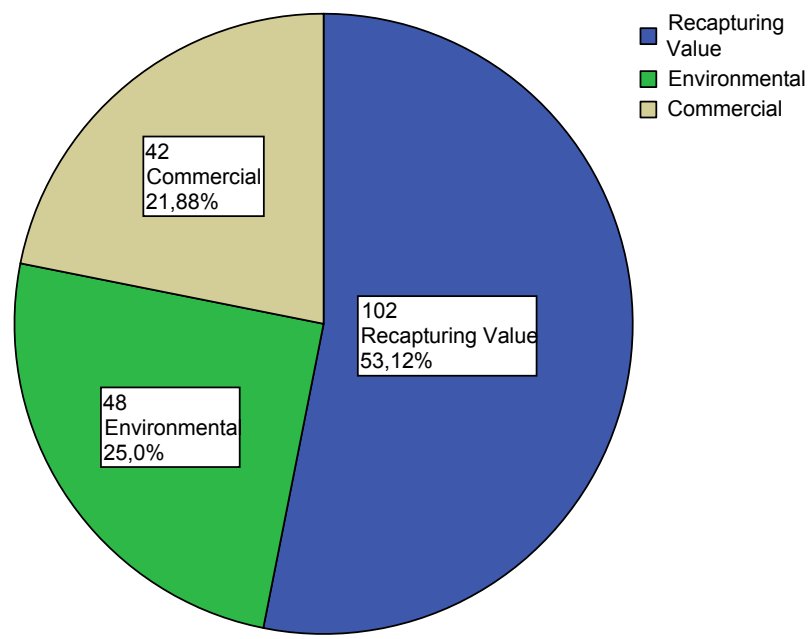

The cluster analysis can originate some artificial classification, for a main reason: the method is extremely subjective in the decision of the clusters quantity. The correct application of this methodology requires the validation of the generated solution. A discriminant analysis has been made with the purpose of verifying if the classification obtained reflects the latent structure in the sample studied. This analysis reinforces the interpretation of the factors that discriminate one group from another. The discriminant analysis is useful for situations where it is required to construct a predictive model of the member number of a group based on the characteristics observed in each case. The procedure of this test generates an output function that can be compared with the predictive variable. In this case the discriminant analysis is made using the function generated by the cluster analysis as predictive variable; therefore the subjectivity in the decision of the quantity of groups 
is eliminated. The result of the discriminant classification shows that the $98 \%$ of cases are correctly classified which means that the classification made with the hierarchical cluster is statistically correct.

The conglomerates obtained by the cluster analysis can contain significant differences between the averages of the variables considered, but they cannot be statistically different from each others. The knowledge of the existence of such differences at certain significant levels is very useful for the classification and characterization of each group formed. It is necessary to study the differences between the averages of the variables in the two dimensions, between the existing groups (differences Inter-group) and in the same group (differences intra-group). The analysis of variance has the objective of verifying that the groups formed are really different from each other. This statistical test is created to know if there are significant differences of the variables averages between the groups.

For the accomplishment of this statistical test, it was proved that the variables are normally distributed applying the Kolmogorov-Smirnov test, and also that the variances between the groups are equal by means of Levene test for homogeneity of variances. In this case the randomness of the sample is not necessary because the data are formed by all the population studied.

The results of ANOVA test demonstrate that there are some significant and remarkable differences between the three groups identified with the cluster analysis in all the variables except the Company Size variable, which is not significant for the classification, so their behavior does not determine any tendency inside the groups. This variable has the same value in most of the cases; it has been evaluated of 3 , (Big companies) 150 out of 192 cases, which means that the company size does not have any incidence in the development of any of the three reverse logistic strategies.

\section{Identification of each group profile}

The behavior of each variable, inside each group, describes the profile of each reverse logistic strategy. The tendencies of a variable can be established through averages and standard deviations. If the average of a variable is significantly greater in a particular group than the average inside the other ones, the incidence of this variable within this group is important for its profile description. Otherwise if a variable has a similar behavior within the different groups, that variable do not have an important weight in the definition of the groups, that is it does not contribute anything to the group description.

Once finished the analysis, there can be recognized a remarkable difference in the variables: supply chain complexity, recapturing value reason, objective to maximize residuals value-added, objective to minimize the return cost of residual and objective to decrease production cost in the Group 1.The environmental reason, objective to reduce the negative environmental impact and competitiveness have a strong importance in the Group 2. And finally, the variables: commercial reason, objective to increase client service, to maximize value-added of returns, objective to decrease return cost of the devolution and the complexity of the reverse supply chain, have a suitable emphasis in the Group 3

After analyzing the reverse logistic strategies behavior in the manufacturing sector of central area of Cuba it is remarkable that most companies (53\% of studied object) follow the Recapturing value strategy. This means that they reuse returns or residuals to decrease the production costs. This strategic tendency is strongly present in the mechanic sector and in the construction material production sector. The environmental character strategies are present in the $25 \%$ of the population. This type of strategy is found in the sugar industry and in the chemical industry. This behavior is caused by the high environmental pollution that this industry generates. The reverse logistic activities carried out by those companies are: proper disposal and the energy obtaining. The presence of the commercial strategy in the industrial sector has not any important tendency. This strategy is followed by competitive companies and is the least common of the reverse logistic strategy types in the manufacturing sector with only $22 \%$ of the sample.

\section{FORMULATION AND FORMALIZATION OF THE REVERSE LOGISTIC STRATEGIES IN THE MANUFACTURING SECTOR}

An interesting result derived from this research is the priority ranking of the most important objectives of the reverse logistic strategies. Table 6 evidences that $26 \%$ of companies confer a high importance to the objective: "to reduce the production costs". The next most ranked objective $(18 \%$ of the requested companies grant it a great importance) is: "to reduce the negative environmental impact". It shows the 
deep interest of the manufacturing companies firstly, in reducing costs and secondly, in the environmental protection. It is also remarkable the low importance given to objective "to recover returns" which is not in contradiction because the fact of returning products implies additional costs in transportation, handling and storages, and most of the companies recapture value from the generated residuals inside their own productive process.

Table 6- Priority ranking of the objectives of reverse logistic strategies in the manufacturing sector

\begin{tabular}{|l|l|l|}
\hline Objectives present in reverse logistic strategies & Ranking & $\mathbf{\%}$ \\
\hline To decrease the production cost & 1 & $26 \%$ \\
\hline To minimize the negative impact on the environment & 2 & $18 \%$ \\
\hline To increase client service & 3 & $14 \%$ \\
\hline To minimize the return cost of devolutions & 3 & $14 \%$ \\
\hline To minimize the return cost of residuals and recycled raw material & 4 & $12 \%$ \\
\hline To maximize the value-added to returned residuals & 5 & $7 \%$ \\
\hline To Maximize value added of returns & 6 & $9 \%$ \\
\hline
\end{tabular}

Same way a ranking of environmental manufacturing policies is established. The most important policies for the studied companies are the usage of non polluting materials, the classification of the residuals generated by the manufacturing companies and the correct storage of dangerous environmental residuals. The least important policies are the design of products for reusage and easy disassembling because the implantation of these policies implies changes in the product designs and it will be more expensive.

The companies were also asked if they actually had a concrete and explicit reverse logistic strategy, whether it was written or not and how often it has been reviewed and reformulated. They were also asked who are in charge of the formulation and formalization of the strategy in each company as well as its correct implementation.

The $48 \%$ of requested companies recognize to have a link between reverse logistic strategies and manufacturing strategies. The $21 \%$ establish a relation between reverse logistic strategies and environmental strategies, and 5\% have a special strategy for the recovering of returns and residuals. It is remarkable that almost $26 \%$ of manufacturing companies in the studied area do not have any strategy for the residual and the return management. It shows how deficient the industrial sector in the Cuba central area is in the strategic aspects of the reverse logistic management. A panoramic view is offered in the Figure 2.

Figure 2- Formulation of reverse logistic strategies in the manufacturing sector of Cuban central area

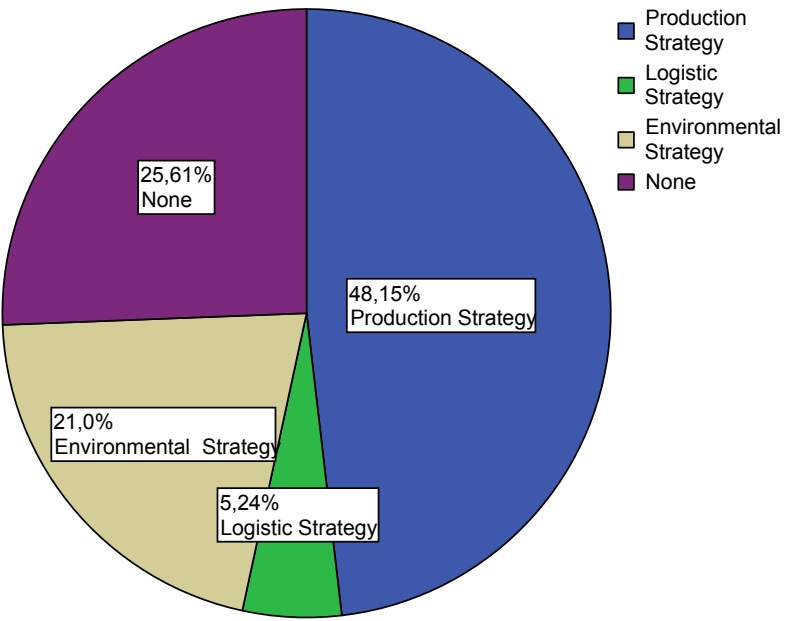

Another interesting aspect lies on the strategy formalization, where only $57 \%$ of those companies whose reverse logistic strategy is implemented, have it properly-written, only $36 \%$ of them have it partially-written and only $7 \%$ do not have any records of their strategy. Competitively it is an undesirable state because these companies can not check if their strategy is working correctly; besides this process can not be certified, which is a competitive disadvantage in market.

The review time of the strategy is another important parameter to take into account in formulating the strategies. The reverse logistic strategies must be periodically reviewed and reformulated in order to adapt them to the new market conditions that companies often have to deal with. The $71 \%$ of the studied manufacturing companies check and reformulate 
their strategies yearly, the $14 \%$ review them from 3 to 5 years, and the other $14 \%$ never check them out. These data reveal that most of companies fix yearly their manufacturing and logistic objectives. In the literature there is not any unanimous agreement of management scientists regarding the right horizon to review the strategies, but they separates: short term (reviews on 1 year term) and long term (reviews on 3-5 years term). Then most of the industrial companies studied emphasize short term objectives to face the earliest competitive challenges not thinking on what can be important in the future. To be competitive it is important to focus in long term priorities or that company will be just a follower.

\section{BEHAVIOR OF RETURNS AND RESIDUALS IN} THE MANUFACTURING SECTOR IN CUBA CEN-

\section{TRAL AREA}

The reuse of the residuals and returns is quite important for companies and for the environment, because it can be a source of economic saving. The reverse logistic strategy will depend in great measure of the residuals generated in each company and its ability to reuse them. High percentages (43\%) of the residuals generated by these industries are organic, which is a challenge for their recovering due to the fast decomposition and the difficult conservation. Another residual that could have some difficulty with its reusability is plastic because of their difficult classification due to the immense amount of plastic types that have similar characteristics. The metallic residuals are also generated in great quantities, $38 \%$ of the residuals generated by the manufacturing companies. These kinds of residuals are easier to be classified and recovered because their recovering does not need relevant changes in the production structure.

In Figure 3 the percentage of companies that reuse the residuals generated by their production processes and what they do with these residuals is shown. The $42 \%$ of the quested companies sell their production process residual to the Recycling Raw Material Company, which adds value to these residuals. This is the most often way used because companies earn money of these sales and other companies will use these materials in their production processes. The $26 \%$ of the companies studied reuse the residuals in their own manufacturing process; the $21 \%$ of them sell residual materials to other companies or retailers; and what is more important, the $11 \%$ do not take advantage of their residuals wasting a great economic saving source.
Figure 3-Residuals recovery in manufacturing companies.



An analysis of the returns, shown in Figure 4, corroborates that high percentage of the companies (52\%) do not manage their possible returns. It is necessary to remark the negative impact that the nonmanaging of the returns may cause to a company. This is one of the most useful weapons in market competition because it provides security and warranty to clients; some other companies may also take back end-life products and remanufacture them, obtaining two possible advantages, first, that the clients do not need to worry about the acquired products at the end of its life, and second, that some product or parts can be remanufactured and reused. The Figure also shows that the $37 \%$ of the companies reuse their returns inside the company sell them to the workers or take them back to market after the remanufacturing process. The rest of the companies (11\%) sell the returned products to other companies or retailers for cannibalization.

Figure 4- Returns recovery in manufacturing companies

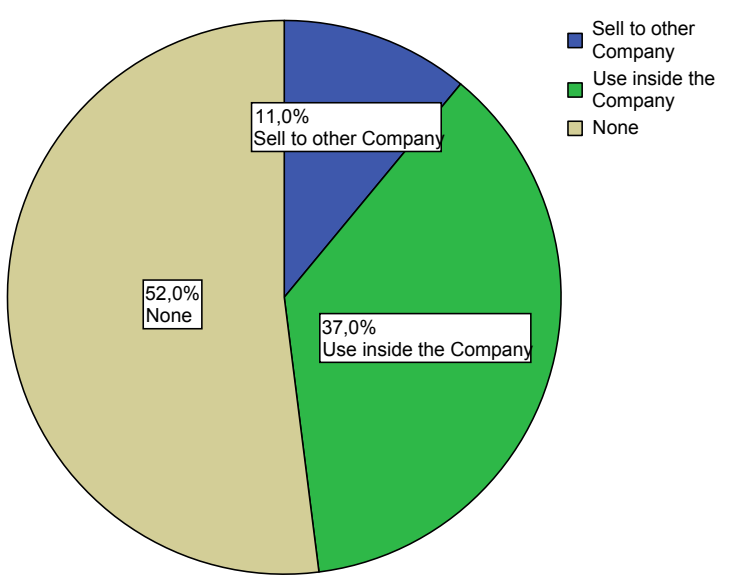


Common problems of reverse logistic strategies found in the study

The reverse logistics differs from forward logistics in many aspects, this principle makes that the common manufacturing and inventory systems cannot be used for the remanufacturing processes and for the reverse logistic networks in all the cases. The planning and control of operations become more complex because of the great uncertainty in the demand of the remanufactured products as well as in the reception of the returns.

The manufacturing sector of central area in Cuba faces the same problems with better or worse solutions. Some of the most common problems that reverse logistic strategies deal with, found in the study are exposed: Lack of software to manage remanufacturing processes; Lack of standard tools to identify components along the remanufacturing processes; Uncertain demand; Uncertain timing, quantity and quality of return, Uncertainty in material recovery; The need to balance return with demand; obsolescence, Disassembly of returned products and Requirement of a reverse logistic network.

\section{CONCLUSIONS}

This paper describes a study in the manufacturing sector in the central area of Cuba, to classify its reverse logistic strategies in generic typologies. At the end of the research, it has been possible to identify three types of reverse logistics strategies in the object studied: Commercial strategies, Environmental strategies and Recapturing value strategies. It also offers the profile of each strategy in the studied sector, it can be used to characterize the reverse logistic strategy developed in another manufacturing company of Cuba.

This research provides a general diagnosis of the reverse logistic status in the sector studied. About 25 percent of companies do not have any strategy for returns and residual management. The 7 percent of the companies do not have it properly written and formalized. It demonstrates the low strategic level reached by companies studied on reverse logistic management. An 11\% of the residuals generated by companies are not recovered, and the $26 \%$ of the companies do not manage their product returns, it means that there are still reserves unexploded.

There still are some problems that companies have to deal with in the reverse logistic field and a challenge that managerial and economic scientists have to face: Lack of standard tools to identify components along the remanufacturing processes; Uncertain demand; Uncertain timing, quantity and quality of return; Core obsolescence; Disassembly of returned products; Requirement of a reverse logistic network among others.

This paper provides a procedure to classify reverse logistic strategies in a manufacturing sector of Cuba, which can be applied in other countries with its proper adjustments. The obtained results can also be compared with studies in other areas, economic sectors or countries offering interesting analysis in the reverse logistic field. This research might be useful for the companies' managers to determine the leader companies inside each cluster in order to realize benchmarking.

\section{REFERENCES}

Alshamrani, A; Mathur, K; Ballou, R. H (2008). Reverse logistics: simultaneous design of delivery routes and returns strategies. Computers \& Operations Research v.34, p.595-619, 2007 In: http://www.sciencedirect.com/science/journal/03054048 Acceso Agosto/2008.

Carter, C. and Ellram, L. (1998) Reverse logistics: a review of the literature and framework for future investigation', Journal of Business Logistics, Vol. 19 No. 1.

Cespón Castro, R. and Ibarra Mirón, S. (2003). Algunas aplicaciones del análisis cluster en la organización de los sistemas de producción intermitentes. Alta Dirección \#229, España.

CHAVES, G De L.D; MARTINS, R.S (2005). Diagnóstico de la Logística Reversa en la Cadena de Abastecimiento de Alimentos Procesados en el Oeste Paranaense. In: VIII Simposio de Administración de la Producción, Logística y Operaciones Internacionales - VIII SIMPOI. São Paulo, 2005. (en Portugués)

Díaz, E. and Martín, M.L. (2004). Configurations in Manufacturing Strategy: An Application to Spanish Industries. Second World Conference on POM and 15th Annual POM Conference.

Feitó Cespón, Michael (2007) Empiric study of reverse logistic strategies in the manufacturing sector of Villa Clara, Cuba a comparison with a Swedish remanufacturing company. Master Thesis. Central University of Las Villas, Santa Clara, Cuba.

González-Torre, P.L., Adenso-Díaz, B. and Artiba, H (2004). Environmental and reverse logistic policies in European bottling and packaging firms, International Journal of Production Economics, Vol. 88.

Grande, I. \& Abascal, E. (1999) Fundamentos y técnicas de investigación comercial. ESIC. Madrid.

Kleindorfer, Paul R, Singhal, Kalyan, Van Wassenhove, Luk N, (2005) Sustainable Operations Management. Product and Operations Management, Vol. 14, No. 4, pp. 482-492

Lau, H.C.W., Lee, C.K.M., Choy, K.L., Ip, W.H., Chan, F.T.S. and Ip, R.W.L. (2004) Implementation of logistic information system to support reverse logistic: a case study', Int. J. Logistic Systems 
and Management, Vol. 1, No. 1.

REVLOG Group (2007). Logística Inversa. www.fbk.eur.nl/OZ/ REVLOG/Introduction.htm

Rogers, Dale S. y Tibben-Lembke, Ronald S. (1998) Going Backwards: Reverse Logistics Trends and Practice, Reverse Logistics Executive Council; Nevada, Reno.
Sinnecker, C. O (2007). Estudio sobre la importancia de la logística reversa en cuatro grandes empresas de la región metropolitana de Curitiba. (Dissertação Mestrado, Pontifícia Universidade Católica de Paraná, 2007) (en Português)

Tibben-Lembke, R. (2002) Life after death: reverse logistic and the product lifecycle. International Journal of Physical Distribution \& Logistic Management, Vol. 32 No. 3, 2002.

\section{AUTHOR'S BIOGRAPHY}

Michael Feitó Cespón: MSc in Logistics and Supply Chain Management, Assistant Professor of Logistics and Supply Chain Management in the Faculty of Industrial Engineering, Central University of Las Villas, Cuba.

Roberto Cespón Castro: PhD in Production and Operation Management, Professor of Logistics and Supply Chain Management in the Faculty of Industrial Engineering Central University of Las Villas, Cuba.

Janerik Ludquist: PhD in Economics, Professor of Economic engineering in the Department of Production Economics, Linköping University, Sweden. 